\title{
El habitar como ser del hombre, según Heidegger ${ }^{1}$
}

Jorge Acevedo Guerra²

Agradezco muy sinceramente la invitación a hablar ante ustedes que me han hecho el Comité de Bioética —en formación-de la Universidad, y la profesora Aylin Bravo. Doy las gracias también al profesor Cristián Valdés, quien insistió en que mi participación en esta reunión

sería oportuna.

$* * *$

Nuestra era es la del predominio de la esencia de la técnica moderna.

Esto significa que, así como en un momento de la historia de Occidente el ser se donó como idea, en nuestro tiempo se destina al hombre -y así lo destina - como lo dis-puesto, la im-posición o la posición-total (das Ge-stell).

A esta destinación del ser corresponde una modulación de la verdad congruente con ella, a saber: el des-ocultar pro-vocante (das herausfordernde Entbergen).

Y el hombre deja de ser históricamente entendido como la creatura hecha a imagen y semejanza de Dios, o como entidad pensante, para ser asumido y tratado como el animal del trabajo (das arbeitende Tier).

Antes de bosquejar un escueto esclarecimiento de lo recién dicho, tengamos presente que en la conferencia de Heidegger «Construir Habitar Pensar» el filósofo medita, de manera decisiva, sobre la esencia del hombre. ¿Y en qué estriba esa esencia? Heidegger indica hacia ella

1 Conferencia dictada en el marco del Coloquio de Bioética, organizado por la académica de la Escuela de Filosofía Aylin Bravo, en junio de 2016.

2 Profesor Titular en el Departamento de Filosofía de la Facultad de Filosofía y Humanidades de la Universidad de Chile. Contacto: joaceved@gmail.com 
echando mano de lo que Ortega llama razón histórica, razón narrativa o razón etimológica ${ }^{3}$.

Reflexionando sobre el estilo filosófico, al recordar el Coloquio de Darmstadt de 1951 en el que Heidegger pronunció esa conferencia, Ortega describe certeramente este modo de pensar.

Nos dice que «consiste en lo siguiente: cada palabra suele poseer una multiplicidad de sentidos que residen en ella estratificados, es decir, unos más superficiales y cotidianos, otros más recónditos y profundos. Heidegger perfora y anula el sentido vulgar y más externo de la palabra y, a presión, hace emerger de su fondo el sentido fundamental de que las significaciones más superficiales vienen, a la vez que lo ocultan. Así la Endlichkeit (finitud) no será meramente una limitación ajena al hombre —-pero que no es el hombre mismo— sino que será todo lo contrario, Seiender Ende o Sein als Ende (ser como fin), con lo cual éste —el Ende (fin) — no queda fuera del hombre como los límites habituales, sino que viene a constituir su esencia misma. El hombre, en efecto, desde que nace está ya muriendo, como dijo Calderón; por tanto, empieza por acabar y vive de su muerte» ${ }^{4}$.

Sea dicho de paso: en «Construir Habitar Pensar», Heidegger habla de los hombres (Menschen), justamente, como de los mortales (die Sterblichen), en la dirección sugerida por Ortega.

Continúa el filósofo español: «Este descenso a los senos profundos, a las vísceras recónditas de la palabra, se hace - yo lo hago desde mi primer libro, Meditaciones del Quijote, 1914- buceando dentro de ella hasta encontrar su etimología o, lo que es igual, su más antiguo sentido. [...] en Heidegger la palabra vulgar súbitamente se llena, se llena hasta los bordes, se llena de sentido. Más aún, nos parece que su uso cotidiano traicionaba a la palabra, la envilecía, y que ahora

3 Véase del autor, La sociedad como proyecto. Santiago, Chile: Editorial Universitaria, 1994, cap. I (en especial, p. 23).

4 Cfr., «En torno al "Coloquio de Darmstadt, 1951"», Obras Completas (en adelante, O. C.), Vol. VI, Madrid: Ed. Taurus/Fundación José Ortega y Gasset, 2006. 807. Cito según esta excelente nueva edición a cargo de Javier Zamora Bonilla. 
vuelve a su verdadero sentido. Este verdadero sentido es lo que los antiguos llamaban el étymon de la palabra. [...] El estilo filosófico de Heidegger - añade Ortega—, tan egregiamente logrado, consiste sobre todo en etimologizar, en acariciar a la palabra en su arcana raíz. [...]. Pone al lector en inmediato contacto con las raíces de la lengua alemana, que son a la vez las raíces del "alma colectiva" alemana» 5 .

En primer lugar, pues, Heidegger toma la palabra bauen, construir, y nos sugiere que tenemos que entenderla a partir de «buan», palabra del alto alemán medieval para construir [bauen], que significa habitar en el sentido de permanecer, mantenerse, conservando una vecindad o cercanía; esto último está insinuado por la palabra Nachbar, vecino -emparentada con las anteriores-, que nos remite a «Nachgebur» $y$ «Nachgebauer», aquel que habita en las cercanías [Nähe]. En suma, «construir [bauen] quiere decir originariamente habitar [wohnen]» ${ }^{6}$.

Segundo: sumergiendo aún más la palabra bauen, construir, en la galaxia semántica correspondiente, Heidegger destaca su vinculación con «bin», soy, en los giros ich bin, yo soy, du bist, tú eres, y en el imperativo bis, sé tú.

Tercero: reuniendo este nexo de bauen, construir, con el que conducía a wohnen, habitar, el filósofo llega a una conclusión de la mayor importancia dentro de su doctrina: «El modo como tú eres y yo soy, la manera según la cual somos los hombres sobre la Tierra, es el Buan, el habitar. Ser hombre quiere decir: ser como mortal sobre la Tierra, quiere decir: habitar. La vieja palabra bauen [construir] dice que el hombre es en cuanto habita»?

En síntesis, la esencia del hombre consiste en habitar.

5 Ibíd. 807 s.

6 Cfr., «Construir Habitar Pensar»; en Filosofía, Ciencia y Técnica. Santiago, Chile: Editorial Universitaria, $5^{\text {a }}$ ed., 2007. 209 s. Trad. de Francisco Soler Grima. Edición de Jorge Acevedo («Bauen Wohnen Denken». Gesamtausgabe (en adelante, GA) Vol. 7: Vorträge und Aufsätze, 2000. 148 s.).

7 lbíd. 210 (lbíd. 149). 
Al profundizar en el examen de la palabra bauen, construir -esto es, habitar - el pensador hace notar que ese Bauen (= Wohnen) se despliega de dos maneras: a) Como cuidar y cultivar; por ejemplo, las viñas en el campo. b) Como edificar; lo que ocurre en la construcción naval, de templos, puentes y casas.

Cuarto: pero es posible dar por lo menos un cuarto paso dentro del campo semántico a que pertenece bauen, construir-habitar. La palabra gótica «wunian» significa, al igual que la vieja palabra bauen, permanecer, mantener-se. Sin embargo, «wunian» permite introducir matices decisivos en bauen y, por tanto, en el habitar en que consiste la esencia del hombre.

«Wunian», en efecto, remite a las palabras Friede, paz, Freie, libre, freien, liberar, las que nos conducen, finalmente, a schonen, proteger, a través de einfrieden, circundar.

Heidegger queda así en condiciones de sacar la conclusión de que el rasgo fundamental del habitar —esto es, de la esencia del hombre-, es el proteger. No obstante, este proteger tiene que entenderse en forma dinámica: no es un mero no hacer nada contra lo protegido, sino un activo retroalbergar algo en su esencia.

En cuatro proposiciones podemos resumir esta exploración etimológica de la palabra bauen.

1. Construir es propiamente habitar.

2. Habitar es el modo como son los mortales sobre la Tierra.

3. El construir como habitar se despliega en el construir que cuida, a saber, el crecimiento, y en el «construir que edifica construcciones» ${ }^{8}$.

4. La característica determinante del habitar, en tanto esencia del hombre, es el proteger, comprendido como el «liberar algo en 
su propia esencia» ${ }^{9}$ - es decir, como salvar (retten)—, custodiando su permanencia en ella.

El habitar genuino está pospuesto y aplastado por el habitar técnico; pero, aunque soterrado y constreñido, está necesariamente ahí, posibilitando su modulación técnica.

En el habitar genuino (o simplemente habitar, a secas; o habitar que merece, sin restricciones, la denominación de tal) encontramos la matriz de todo otro.

En él — dicho en esbozo-, los mortales se mantienen en medio de las cosas y junto a ellas, dentro del juego de la Unicuadridad (a la que me refiero a continuación).

La palabra «cosa» no tiene en el Heidegger maduro un sentido peyorativo, como en otras filosofías. La cosificación es algo que eleva y no un descenso ontológico.

Algo — un puente, una jarra, un vaso de plata para el sacrificio religioso, una casa, un sendero de campo ${ }^{10}$ — alcanza el rango de cosa cuando reúne al ser entendido como la Unicuadridad, lo cuadrante, la Cuaterna o la Cuaternidad (das Geviert): Cielo, Tierra, Mortales y Divinos.

Consideremos un ejemplo que aparece en la conferencia «Construir Habitar Pensar»:

«Pensemos por un rato — dice Heidegger-, en una casa de campo [Hof] de la Selva Negra, la cual construyó todavía el habitar campesino hace dos siglos. Aquí la in-stancia del poder de dejar introducir en las cosas, desplegándose unitariamente, a Tierra y Cielo, los Divinos y los Mortales, ha dirigido la casa.

9 lbíd. 214 (Ibíd. 152).

10 Al respecto, véase Heidegger, M. Camino de campo/Der Felweg. Barcelona: Ed. Herder, 2003. Trad. de Carlota Rubies; Heidegger, M. "El camino del campo". En: Experiencias del pensar (1910-1976). Madrid: Ed. Abada, 2014, 47-50. Trad. de Francisco de Lara (GA 13: Aus der Erfahrung des Denkens. 87-90). 
$1^{\circ}$ Ha puesto la casa de campo [Hof] en la ladera de la montaña, protegida de los vientos, contra el mediodía, entre la pradera, en la cercanía de los manantiales.

$2^{\circ}$ Se le ha puesto el tejado con mucho resalte, tejado que soporta con su inclinación adecuada el peso de la nieve y llegando muy abajo, protege a los aposentos de las tormentas de las largas noches invernales.

$3^{\circ}$ No se ha olvidado el rincón-de-Dios detrás de la mesa común,

$4^{\circ}$ Se ha espaciado el lugar sagrado para el puerperio y el árbol del muerto [Totenbaum] —así se llama allí el ataúd—en los aposentos, y así ha diseñado a las diferentes edades de la vida, bajo un techo, el cuño de su curso a través del tiempo.

$5^{\circ}$ Una artesanía, originada en el mismo habitar, que emplea aún sus herramientas y andamios como cosas, ha construido la casa de campo $[\text { Hof }]^{11}$.

El modo de la verdad en que se manifiesta el ser como la Unicuadridad no es, sin duda, el des-ocultar pro-vocante, ínsito en la voluntad de poder inherente a la destinación del ser que caracteriza la época del predominio de la esencia de la técnica moderna.

Así, pues, cuando el hombre habita genuinamente no se ve impelido a des-ocultar a priori a los entes - entre los cuales está él mismo- en el horizonte de la utilización absoluta y extrema. Por el contrario, en tal caso el hombre existe de-velando en forma acogedora y respetuosa todo cuanto hay, dejándolo ser lo que esencialmente es, y protegiéndolo en su residir en lo que le es más propio.

Por otra parte, los mortales no se reducen a ser el animal del trabajo que busca la mayor eficacia, con el mínimo esfuerzo, a través del pensar computante, que avanza en línea recta hacia sus objetivos, sin mayores miramientos respecto de nada ni nadie.

11 «Construir Habitar Pensar», ed. cit. 226 s. («Bauen Wohnen Denken». GA 7. 162). La puntualización es mía. 
En cuanto custodios de la esencia de la verdad y seres meditativos, ponen en juego un pensar concordante con ello, el pensar meditativo (besinnliches Nachdenken) que, como su nombre lo indica en alemán, persigue el sentido ( $\operatorname{Sinn}$ ) de todo cuanto acontece, complementando en forma decisiva al pensar calculante (rechnendes Denken).

Los hombres que habitan genuinamente no se quedan en el lenguaje como simple instrumento de información. Sabiéndolo o no, lo asumen como la casa del ser, la morada de los mortales. ¿Qué quiere decir esto?

En mi concepto, un penetrante párrafo de Ortega nos sitúa, por el camino más corto y claro, en el núcleo del asunto. Dilucidando la noción de duda vital, advierte que «en este punto, como en tantos otros referentes a la vida humana, recibimos mayores esclarecimientos del lenguaje vulgar que del pensamiento científico. Los pensadores —agrega - [...] se han saltado [...] aquella realidad radical, la han dejado a su espalda. En cambio, el hombre no pensador, más atento a lo decisivo, ha echado agudas miradas sobre su propia existencia y ha dejado en el lenguaje vernáculo el precipitado de esas entrevisiones. Olvidamos demasiado que el lenguaje es ya pensamiento, doctrina. Al usarlo como instrumento, para combinaciones ideológicas más complicadas, no tomamos en serio la ideología primaria que él expresa, que él es. Cuando, por un azar, nos despreocupamos de lo que queremos decir nosotros mediante los giros preestablecidos del idioma y atendemos a lo que ellos nos dicen por su propia cuenta, nos sorprende su agudeza, su perspicaz descubrimiento de la realidad» ${ }^{12}$.

Y a propósito de esto mismo, creo que no hay que olvidar este decir de Antonio Machado: «Hemos de vivir en un mundo sustentado sobre unas cuantas palabras, y si las destruimos, tendremos que sustituirlas por otras. Ellas son los verdaderos atlas del mundo; si una de ellas nos falta antes de tiempo, nuestro universo se arruina» ${ }^{13}$.

12 Cfr., Ideas y Creencias. O. C. Vol. V, 2006. 670. Énfasis añadido.

13 Cfr., «Juan de Mairena»; en Obras Completas, de Manuel y de Antonio Machado. Madrid: Editorial Plenitud, $5^{\text {a }}$ ed., 1967. 1167. Texto al cuidado de Heliodoro Carpintero/Antonio Machado, Obras Completas Vol. I. Buenos Aires y Barcelona: 
En el habitar que estamos bosquejando, tiempo y espacio son vivenciados de una particular manera.

La rapidez, la instantaneidad y la simultaneidad perseguidas obsesivamente por el hombre moderno, son reemplazadas por el repique de la calma y la serenidad (die Heiterkeit). «En el pensar — señala Heidegger-, cada cosa deviene solitaria y lenta. / En la paciencia prospera la magnanimidad» ${ }^{14}$.

Precisando la «vinculación» del ser humano con el tiempo, Francisco Soler escribe al final de su último ensayo: «Así, podríamos proponer como bien para los hombres: que cada cual encuentre su propio ritmo en trama con los prójimos y con la "Naturaleza"»15.

Calma y serenidad, lentitud y paciencia, búsqueda del propio ritmo: palabras claves para desentrañar el habitar auténtico en lo que al tiempo atañe.

En un texto referido a su propia persona - «¿Por qué permanecemos en la provincia?»—, Heidegger nos proporciona dos pistas de gran importancia para dilucidar la experiencia del espacio en el habitar genuino. Por un lado, compara el contorno de su cabaña — situada en el valle de Todnau - visto por un turista, con la modalidad en que él lo vivencia. Dice en el párrafo más significativo para nuestros propósitos:

«Yo mismo nunca miro realmente el paisaje. Siento su transformación continua, de día y de noche, en el gran ir y venir de las estaciones. La pesadez de la montaña y la dureza de la roca primitiva, el contenido crecer de los abetos, la gala luminosa y sencilla de los prados florecientes, el murmullo del arroyo de la montaña en la vasta noche del otoño, la austera sencillez de los llanos totalmente recubiertos de

Ed Losada, $4^{a}$ ed., 1997. 596. Edición de Aurora de Albornoz y Guillermo de Torre. 14 Cfr. «La experiencia del pensar»; en La experiencia del pensar, seguido de Hebel, el amigo de la casa, ed. cit. 37. Traducción, introducción y notas de Arturo García Astrada («Aus der Erfahrung des Denkens». GA 13. 81).

15 Cfr. Apuntes acerca del pensar de Heidegger. Santiago, Chile: Ed. Andrés Bello, 1983. 234. Edición a cargo de Jorge Acevedo. 
nieve, todo esto se apiña y se agolpa y vibra allá arriba a través de la existencia diaria.

$\mathrm{Y}$, nuevamente, esto no ocurre en los instantes deseados de una sumersión gozosa o de una compenetración artificial, sino, solamente, cuando la propia existencia se encuentra en su trabajo. Sólo el trabajo abre el ámbito de la realidad de la montaña. La marcha del trabajo permanece hundida en el acontecer del paisaje» ${ }^{16}$.

Por otro lado, se refiere a la peculiar soledad que siente en su cabaña campestre, señalando que «los hombres de la ciudad se maravillan a menudo de este largo y monótono quedarse solo entre los campesinos y las montañas. Sin embargo —aclara—, esto no es ningún quedarse solo; pero sí soledad. En verdad —añade—, en las grandes ciudades el hombre puede quedarse solo como apenas le es posible en cualquier otra parte. Pero allí nunca puede estar a solas. Pues la auténtica soledad tiene la fuerza primigenia que no nos aísla, sino que arroja la existencia humana total en la extensa vecindad de la esencia de todas las cosas» ${ }^{17}$.

El particular ritmo del propio trabajo, y la especial soledad que no aísla, sino que nos lanza a la vecindad de las cosas son, pues, de acuerdo con nuestro pensador, dos modos del adverar, del des-encubrir, de la alétheia (de la verdad como des-encubrimiento) que nos abren propiamente al espacio del mundo en torno y a los entes intramundanos ${ }^{18}$.

\footnotetext{
16 Véase Revista Universitaria (P. Universidad Católica de Chile) Vol. XV, Santiago, segundo semestre de 1985. Trad. de Jorge Rodríguez / M. Heidegger: «Paisaje creador: ¿Por qué permanecemos en la provincia?» En: Experiencias del pensar (1910-1976), ed. cit. 15 ("Schöpferische Landschaft: Warum bleiben wir in der Provinz? (1933)". GA 13.9 s.).

17 lbíd. / Ibíd. 17 (Ibíd. 11).

18 Para mayores desarrollos respecto de lo planteado, véase, del autor, Heidegger y la época técnica. Santiago, Chile: Ed. Universitaria, 2016.
} 